\title{
Effect of learning curve on the perioperative course of robotic-assisted laparoscopic donor nephrectomy compared with laparoscopic donor nephrectomy
}

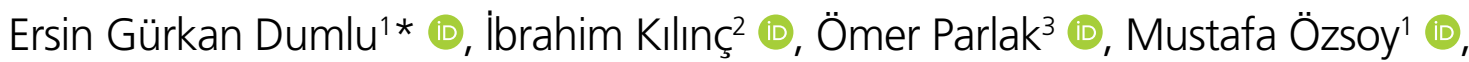 \\ Bahar Demirci3 (1), Şebnem Karakan³ (1), Mehmet Kilic ${ }^{4}$ (1)
}

\begin{abstract}
SUMMARY
OBJECTIVE: This study was designed to compare the standard and robotic-assisted laparoscopic donor nephrectomy in terms of perioperative course, short-term postoperative outcome, and to evaluate the effect of surgeon's learning curve on these parameters. METHODS: This was a prospective randomized study including 60 patients (mean age, 47 years; age, 21-72 years; 26 males, 34 females) who had been planned laparoscopic donor nephrectomies in our clinic. For comparison of standard and robot-assisted techniques and to evaluate the impact of learning curve, patients were randomized into three groups by a computer, each group containing 20 patients. Group 1: standard laparoscopic donor nephrectomies; Group 2: the first 20 patients who underwent robot-assisted laparoscopic donor nephrectomy; and Group 3: the next 20 patients who underwent robot-assisted laparoscopic donor nephrectomy.

RESULTS: Operative time was significantly higher in Group 2 (221.0 $\pm 45.1 \mathrm{~min})$ than both Group 1 (183.5 $\pm 16.9 \mathrm{~min}, \mathrm{p}=0.001)$ and Group 3 (186.5 $\pm 20.6 \mathrm{~min}, \mathrm{p}=0.002$ ). Similarly, time for laparoscopic system setup was significantly higher in Group 2 (39.5 $\pm 8.6 \mathrm{~min}$ ), which contained the first cases of robot-assisted laparoscopic donor nephrectomy where surgeon had least experience than Group 1 (19.3 $\pm 3.7 \mathrm{~min}, \mathrm{p}<0.001)$ and Group $3(24.0 \pm 9.4 \mathrm{~min}, \mathrm{p}<0.001)$. On the other hand, duration of operation and time for laparoscopic system setup was similar between Groups 1 and 3.

CONCLUSIONS: Learning curve extends the operative time and laparoscopic system setup time in robotic-assisted laparoscopic donor nephrectomy, however, after the learning process was completed, these parameters were similar between robotic-assisted and standard laparoscopic nephrectomy.

KEYWORDS: Laparoscopy. Nephrectomy. Robotics. Renal transplantation. Donor.
\end{abstract}

\section{INTRODUCTION}

Renal transplantation is the most effective treatment for patients with end-stage renal failure. However, the increasing number of patients on the kidney waiting list along with the lack of kidney available for transplantation is a common problem in this area. For this reason, living donor kidney transplantation has become an increasingly preferred practice ${ }^{1}$. The living donor nephrectomy can be done either with conventional open technique or laparoscopic technique, which gained widespread acceptance in the last decades. Although there is no difference between these two techniques in terms of organ function, laparoscopic donor nephrectomy

\footnotetext{
'Yıldırım Beyazıt University, Faculty of Medicine, Department of General Surgery - Ankara, Turkey.

${ }^{2}$ Ataturk Research and Training Hospital, Department of General Surgery - Ankara, Turkey.

${ }^{3}$ Ankara Yıldırım Beyazıt University, Faculty of Medicine, Department of Nephrology - Ankara, Turkey.

${ }^{4}$ Osmangazi Faculty of Medicine, Department of General Surgery - Eskișehir, Turkey.

${ }^{\star}$ Corresponding author: gurkandumlu@gmail.com

Conflicts of interest: the authors declare there is no conflicts of interest. Funding: none.

Received on June 01, 2021. Accepted on June 17, 2021.
} 
is associated with less postoperative pain, faster recovery, and better cosmetic results ${ }^{2,3}$. For this reason, laparoscopy, which has been first implemented in $1995^{4}$, has been widely used since then in donor nephrectomy, and increased the number of live kidney donations ${ }^{5}$.

Laparoscopic donor nephrectomy has been performed with the aid of a two-dimensional image obtained with a single camera. However, the da Vinci Robotic Surgical System (Intuitive Surgical Inc., Sunnyvale, CA, USA), developed in recent years, enabled robotic-assisted laparoscopic procedures $^{6}$. In this system, a three-dimensional image with a sense of depth is provided, and the operation area can be enlarged 10-12 times ${ }^{7,8}$. These advantages offer remarkable comfort to the surgeon who performs the surgery. Previous reports proved that in comparison with standard laparoscopic donor nephrectomy, robotic-assisted donor nephrectomy provides better renal function, lower morbidity, and shorter hospital stay even in the presence of vascular anomalies ${ }^{9-12}$. However, system and procedural training and practice, commonly referred as learning curve, is needed for surgeons to master the da Vinci Robotic Surgical System ${ }^{13-15}$.

In this study, we aimed to present our experience with robotic-assisted laparoscopic donor nephrectomy in our clinic, to compare the standard and robotic-assisted laparoscopic donor nephrectomy in terms of perioperative course and short-term postoperative outcome, and to evaluate the effect of learning curve of surgeon on these parameters.

\section{METHODS}

This was a prospective randomized study including 60 consecutive patients (mean age, 47 years; age range, 21-72 years; 26 males and 34 females) who had been planned laparoscopic donor nephrectomies in our clinic. Laparoscopic donor nephrectomies were performed by one surgeon who had experience on laparoscopic surgery.

For comparison of standard and robot-assisted techniques and to evaluate the impact of learning curve, patients were randomized into three groups by a computer. Group 1 was formed by standard laparoscopic donor nephrectomies, Group 2 was formed by the first 20 patients who underwent robot-assisted laparoscopic donor nephrectomy, and Group 3 was formed by the latter 20 patients who underwent robot-assisted laparoscopic donor nephrectomy.

The study was conducted in accordance to the latest version of Helsinki Declaracation and approved by the Institutional Ethics Committtee of Ankara Yıldırım Beyazıt University Faculty of Medicine (no 26,379,996/216). All donors were informed about the study and gave ata otomotiv written consent.

\section{Surgical procedures}

\section{Standard laparoscopic donor nephrectomy}

While the patient was in the lumbotomy position and under general anesthesia, a $10 \mathrm{~mm}$ port was placed into the abdomen through a $1 \mathrm{~cm}$ incision made on the midclavicular line approximately $5 \mathrm{~cm}$ from the left side of the umbilicus. Standard gas insufflation was performed to obtain an intra-abdominal pressure of $13 \mathrm{mmHg}$. Subsequently, under direct vision, two ports were inserted at $10 \mathrm{~mm}$ from the left arcus costarum midclavicular line junction and $5 \mathrm{~mm}$ from the left lumbar region, respectively. The ureter was dissected until the iliac vascular structure. Suprarenal and gonadal veins were clipped and cut. All the dissections were performed by using LigaSure ${ }^{\mathrm{Tm}}$ Maryland Jaw Laparoscopic Sealer/Divider (Medtronic, USA). Subsequently, peritoneum was reached by cutting the percutaneous and subcutaneous fat tissue and muscles with a transverse incision of about $5 \mathrm{~cm}$ in the lower quadrant. When renal transplant patient is ready, ureter was cut after placing Hem-o$\operatorname{lok}^{\oplus}$ clip (Teleflex Incorporated, Wayne, PA, USA). Afterwards, renal artery and renal vein were cut by using vascular endoscopic stapler (Endo-GIA, Covidien PLC, USA). The kidney was taken out from the incision in the left lower quadrant.

\section{Robotic-assisted laparoscopic donor nephrectomy}

While the patient was in the lumbotomy position and under general anesthesia, the peritoneum was reached by cutting the percutaneous and subcutaneous fat tissue and muscles through a transverse $5 \mathrm{~cm}$ incision in the lower left quadrant. A $15 \mathrm{~mm}$ port was placed, and standard gas insufflation was performed to obtain an intra-abdominal pressure of $13 \mathrm{mmHg}$. An $8 \mathrm{~mm}$ port was placed into the abdomen through a $1 \mathrm{~cm}$ incision made on the midclavicular line approximately $5 \mathrm{~cm}$ from the left side of the umbilicus. Subsequently, under direct vision, two ports were inserted at $8 \mathrm{~mm}$ from the left arcus costarum midclavicular line junction and $8 \mathrm{~mm}$ from the left lower quadrant, respectively. Ports were matched with Da Vinci robot. The ureter was dissected until the iliac vascular structure. Left suprarenal and gonadal veins were clipped and cut. When renal transplant patient is ready, ureter was cut after placing Hem-o-lok ${ }^{\circledR}$ clip (Teleflex Incorporated). Afterwards, renal artery and renal vein were cut by using vascular endoscopic stapler (Endo-GIA, Covidien PLC). The kidney was taken out from the incision in the left lower quadrant.

\section{Outcome measures}

Patients were followed up postoperatively until discharge from hospital. The following pre-, peri-, and postoperative parameters were recorded: age, gender, body mass index (BMI), previous abdominal operations, preoperative donor kidney size 
by ultrasonography, the American Society of Anesthesiologists (ASA) physical status classification, laparoscopic system setup time, number of renal arteries, complications, conversion to open nephrectomy, operative time, primary warm ischemia time, and drain volume on the first postoperative day.

\section{Statistical analysis}

Study data were summarized by using descriptive statistics, which were mean and standard deviation for continuous variables, and frequency and percentage for categorical variables. Shapiro-Wilk's test was used for testing normal distribution. Since study data were normally distributed, the significance of the difference between the independent groups was examined with the Student's $t$ test for two groups and by the analysis of variance test for more than two groups. Post hoc Tukey test was used to make pair-wise comparisons between groups. The analysis of categorical data in cross tables was performed by the chi-square or the Fisher's exact test. Analysis of the data was performed by the IBM SPSS Statistics 20.0 software (IBM Corporation, Armonk, NY, USA). The results were considered statistically significant when $\mathrm{p}<0.05$.

\section{RESULTS}

Study groups were comparable with respect to gender, age, and BMI $(p>0.05)$. APA physical status score was 2 or lower for all donors, indicating that patients were either healthy or had a mild systemic disease (Table 1). A total of 10 patients had a history for a previous abdominal operation (cesarean section in 5 patients, total abdominal hysterectomy+bilateral salpingo-oophorectomy in 2 patients, inguinal hernia repair in 2 patients, and laparoscopic cholecystectomy in 1 patient). Study group did not show significant difference in terms of APA score and previous abdominal operation (Table 1). Double renal arteries were present in 7 (11.7\%) patients (3 in Group 1, 26 in Group 2, and 2 in Group $3 ; \mathrm{p}=0.944)$. Conversion to open nephrectomy was required for two patients, both in Group 2, for bleeding in one patient and difficulty in anatomic dissection in other one (Table 1).

Only one patient, who was among the first cases of robot-assisted laparoscopic donor nephrectomy, had a postoperative complication, chylous fistula. None of the other donors had any postoperative complication (Table 1).

There was also no difference between study groups in terms of donor or remnant kidney size, primary warm ischemia time, and drain volume on first postoperative day (Table 2). However, duration of operation was significantly higher in Group 2 (221.0 $\pm 45.1 \mathrm{~min})$ than both Group 1 (183.5 \pm 16.9 $\min , \mathrm{p}=0.001)$ and Group $3(186.5 \pm 20.6 \mathrm{~min}, \mathrm{p}=0.002)$. Similarly, time for laparoscopic system setup was significantly higher in Group 2 (39.5 $\pm 8.6 \mathrm{~min}$ ), which contained the first cases of robot-assisted laparoscopic donor nephrectomy where surgeon had least experience than both Group 1 (19.3 \pm 3.7 min, $\mathrm{p}<0.001)$ and Group $3(24.0 \pm 9.4 \mathrm{~min}, \mathrm{p}<0.001$; Table 2). In contrast, duration of operation and time for laparoscopic system setup was similar between Groups 1 and 3 (Table 2).

Table 1. Demographic and clinical characteristics of study groups (categorical variables).

\begin{tabular}{l|c|c|c|c|c}
\multicolumn{1}{l|}{} & & $\begin{array}{c}\text { Group 1 } \\
\text { Standard LDN } \\
(n=20)\end{array}$ & $\begin{array}{c}\text { Group 2 First cases } \\
\text { of robot-assisted } \\
\text { LDN }(n=20)\end{array}$ & $\begin{array}{c}\text { Group 3 Later cases } \\
\text { of robot-assisted } \\
\text { LDN (n=20) }\end{array}$ & $p$ \\
\hline \multirow{2}{*}{ Sex (male/female) } & 1 & $0 / 11$ & $9 / 11$ & $8 / 12$ & 0.865 \\
\cline { 2 - 5 } & 2 & $20(100.0 \%)$ & $17(85.0 \%)$ & $19(95.0 \%)$ & \multirow{2}{*}{0.844} \\
\cline { 2 - 5 } & 3 & $0(0 \%)$ & $1(5.0 \%)$ & $0(0 \%)$ & \\
\hline Previous abdominal operation* & & $3(15.0 \%)$ & $4(20.0 \%)$ & $3(15.0 \%)$ & 0.937 \\
\hline Conversion to open nephrectomy & & $0(0 \%)$ & $2(10.0 \%)$ & $0(0 \%)$ & 0.985 \\
\hline Rate of complications & & $0(0 \%)$ & $1 \neq(5.0 \%)$ & $0(0 \%)$ & 0.985 \\
\hline \multirow{2}{*}{ Number of renal arteries } & 1 & $17(85.0 \%)$ & $18(90.0 \%)$ & $18(90.0 \%)$ & \multirow{2}{*}{0.944} \\
\cline { 2 - 5 } & 2 & $3(15.0 \%)$ & $2(10.0 \%)$ & $2(10.0 \%)$ & $0.0 \%)$ \\
\hline
\end{tabular}

LDN: laparoscopic donor nephrectomy; ASA: The American Society of Anesthesiologists. According to ASA physical status classification, ASA 1 indicates a normal healthy patient and ASA 2 indicates a patient with mild systemic disease, and ASA 3 indicates a patient with severe systemic disease that is a constant threat to life.

*2 cesarean sections, 1 inguinal hernia repair in Group 1; 2 cesarean sections, 2 total abdominal hysterectomy+bilateral salpingo-oophorectomy in Group 2; and 1 cesarean sections, 1 inguinal hernia repair, 1 laparoscopic cholecystectomy in Group 3; ${ }^{+}$Conversion to open nephrectomy was performed for bleeding in one patient, and difficulty in anatomic dissection in another patient; ${ }^{\ddagger}$ Chylous fistula. 
Table 2. Clinical, operative, and postoperative findings of study groups (continuous variables).

\begin{tabular}{|c|c|c|c|c|c|c|c|}
\hline & \multirow{2}{*}{$\begin{array}{l}\text { Group } 1 \\
\text { Standard } \\
\text { LDN } \\
(n=20)\end{array}$} & \multirow{2}{*}{$\begin{array}{c}\text { Group } 2 \\
\text { First cases of } \\
\text { robot-assisted } \\
\text { LDN }(n=20)\end{array}$} & \multirow{2}{*}{$\begin{array}{l}\text { Group } 3 \\
\text { Later cases of } \\
\text { robot-assisted } \\
\text { LDN }(n=20)\end{array}$} & \multicolumn{3}{|c|}{$\begin{array}{l}\text { p value for pair-wise } \\
\text { comparison }\end{array}$} \\
\hline & & & & & \begin{tabular}{|l|} 
Groups 1 \\
versus 2
\end{tabular} & \begin{tabular}{|l|} 
Groups 1 \\
versus 3
\end{tabular} & $\begin{array}{l}\text { Groups } 2 \\
\text { versus } 3\end{array}$ \\
\hline \multicolumn{2}{|l|}{ Age (years) } & $44(21-69)$ & $40(24-72)$ & $39(26-68)$ & - & - & - \\
\hline \multicolumn{2}{|l|}{ Body mass index $\left(\mathrm{kg} / \mathrm{m}^{2}\right)$} & $25.8 \pm 4.0$ & $28.1 \pm 4.2$ & $27.6 \pm 4.6$ & 0.218 & 0.317 & 0.936 \\
\hline \multirow{2}{*}{$\begin{array}{l}\text { Donor kidney size on } \\
\text { preoperative US (mm) }\end{array}$} & Length & $105.4 \pm 8.2$ & $106.7 \pm 8.9$ & $104.9 \pm 8.3$ & 0.886 & 0.981 & 0.789 \\
\hline & Width & $47.4 \pm 6.0$ & $45.7 \pm 5.8$ & $45.6 \pm 7.1$ & 0.659 & 0.653 & 0.985 \\
\hline \multicolumn{2}{|c|}{ Primary warm ischemia time (s) } & $115.0 \pm 14.4$ & $96.6 \pm 19.7$ & $106.7 \pm 21.0$ & 0.635 & 0.342 & 0.205 \\
\hline \multicolumn{2}{|c|}{ Laparoscopic system setup time (min) } & $19.3 \pm 3.7$ & $39.5 \pm 8.6$ & $24.0 \pm 9.4$ & $<0.001$ & 0.131 & $<0.001$ \\
\hline \multicolumn{2}{|l|}{ Operative time (min) } & $183.5 \pm 16.9$ & $221.0 \pm 45.1$ & $186.5 \pm 20.6$ & 0.001 & 0.947 & 0.002 \\
\hline \multicolumn{2}{|c|}{ Drain volume on 1st postop day $(\mathrm{mL})$} & $53.5 \pm 25.4$ & $67.0 \pm 36.9$ & $66.5 \pm 37.3$ & 0.418 & 0.415 & 0.999 \\
\hline
\end{tabular}

LDN: laparoscopic donor nephrectomy; US: ultrasonography. Data are given as mean (range) or meantstandard deviation.

\section{DISCUSSION}

In this study, we primarily showed that learning curve extends the operative time and laparoscopic setup time in robotic-assisted laparoscopic donor nephrectomy.

Laparoscopic donor nephrectomy has become the procedure of choice in living kidney donor transplantation ${ }^{16}$. Since the publication of first series of robotic-assisted laparoscopic donor nephrectomy, robotic-assisted surgery has become the most preferred technique with various advantages to surgeon and patient ${ }^{7,17}$. It improves patient safety with minimal rate of complications and conversion to open surgery and provides short hospital stays allowing donor patient to return normal life earlier and decreasing total cost of procedure ${ }^{11,18}$. Recent studies even improved the cosmetic outcomes of robotic-assisted donor nephrectomy by using single-site platform, however, there is still need for further study to evaluate benefit of this technique considering its increased cost and complexity ${ }^{19,20}$. Although recent advances in robotic-assisted surgery also allowed shortening of learning curve of surgeons, it is necessary to be performed by a well-trained and experienced surgical team in order to obtain best surgical and clinical outcome ${ }^{18}$.

Horgan et al. ${ }^{18}$ evaluated 214 robotically assisted donor nephrectomies and found that only 4 patients converted to open surgery, the mean warm ischemia time was $98 \mathrm{~s}$ and the operative time was $201 \mathrm{~min}$ for the first cases and $103 \mathrm{~min}$ for the last cases $(\mathrm{p}<0.001)$, and complications decreased significantly after the first cases. Similarly, in our study, conversion to open nephrectomy was required for two patients, both being the first cases of robot-assisted laparoscopic donor nephrectomy, for bleeding in one patient and difficulty in anatomic dissection in other one. In this group, only 1 patient had a postoperative complication, which was chylous fistula. None of the patients in standard laparoscopy group or later cases of robot-assisted laparoscopic donor nephrectomy group experienced any postoperative complications. The warm ischemia time was $96.6 \mathrm{~s}$ for first cases robot-assisted laparoscopic donor nephrectomy, which was not significantly different than standard laparoscopy. Laplace et al. ${ }^{10}$ reported that in 100 cases of robotic-assisted laparoscopic living donor nephrectomy, mean operative time and warm ischemia time were $174 \mathrm{~min}$ and $4.8 \mathrm{~min}$, respectively. In the present study, although the operative time was longer in first robot-assisted cases $(221.0 \pm 45.1 \mathrm{~min})$ than standard laparoscopy cases (183.5 $\pm 16.9 \mathrm{~min}, \mathrm{p}=0.001)$, it was significantly shortened in late robot-assisted cases $(186.5 \pm 20.6 \mathrm{~min}$ ) and became similar to standard laparoscopy group. Similarly, time for laparoscopic system setup was significantly higher in first robot-assisted cases (39.5 $\pm 8.6 \mathrm{~min})$ than standard laparoscopy group $(19.3 \pm 3.7 \mathrm{~min})$, but in late robot-assisted cases this duration was not significantly different from standard laparoscopy group $(24.0 \pm 9.4 \mathrm{~min})$. These findings suggest that as the experience of surgeon increases, time required for operation and laparoscopic system setup does not show significant difference between standard and robot-assisted laparoscopic donor nephrectomy. Our findings was also similar to the finding of a recent study by Yang et al..$^{21}$.

The main limitation of our study was the lack of assessment of critical clinical outcomes for donor nephrectomy surgery such as renal function, morbidity, and hospital stay, which limits effective comparison of robotic-assisted donor nephrectomy and standard laparoscopic donor nephrectomy.

\section{CONCLUSIONS}

As the experience of surgeon increases in the robotic surgery, the time needed for laparoscopic system setup and operation gets shorter approaching standard laparoscopic donor nephrectomy. Our findings did not show a clear advantage of 
robot-assisted laparoscopic donor nephrectomy over standard laparoscopic nephrectomy during perioperative and short-term postoperative course. Further cost-benefit studies are needed to conclude on the advantages of robot-assisted laparoscopic donor nephrectomy.

\section{AUTHORS CONTRIBUTIONS}

EGD: Conceptualization, Writing - original draft, Writing - review \& editing. IK: Data curation. OP: Formal analysis. MO: Project administration. BD: Software. SK: Methodology.

MK: Supervision, Investigation.

\section{REFERENCES}

1. Sawinski D, Locke JE. Evaluation of kidney donors: core curriculum 2018. Am J Kidney Dis. 2018;71(5):737-47. https:// doi.org/10.1053/j.ajkd.2017.10.018

2. Eng M. The role of laparoscopic donor nephrectomy in renal transplantation. Am Surg. 2010;76(4):349-53. PMID: 20420241

3. Fonouni $H$, Mehrabi A, Golriz M, Zeier M, Müller-Stich BP, Schemmer $\mathrm{P}$, et al. Comparison of the laparoscopic versus open live donor nephrectomy: an overview of surgical complications and outcome. Langenbecks Arch Surg. 2014;399(5):543-51. https://doi.org/10.1007/s00423-014-1196-4

4. Ratner LE, Ciseck LJ, Moore RG, Cigarroa FG, Kaufman HS, Kavoussi LR. Laparoscopic live donor nephrectomy. Transplantation. 1995;60(9):1047-9. PMID: 7491680

5. Schweitzer EJ, Wilson J, Jacobs S, Machan CH, Philosophe B, Farney A, et al. Increased rates of donation with laparoscopic donor nephrectomy. Ann Surg. 2000;232(3):392-400. https:// doi.org/10.1097/00000658-200009000-00011

6. Hoznek A, Hubert J, Antiphon P, Gettman MT, Hemal AK, Abbou CC. Robotic renal surgery. Urol Clin North Am. 2004;31(4):731-6. https://doi.org/10.1016/j.ucl.2004.06.015

7. Horgan S, Vanuno D, Sileri P, Cicalese L, Benedetti E. Robotic-assisted laparoscopic donor nephrectomy for kidney transplantation. Transplantation. 2002;73(9):1474-9. https:// doi.org/10.1097/00007890-200205150-00018

8. Kaul S, Menon M. Robotics in laparoscopic urology. Min Invasive Ther Allied Technol. 2005;14(2):62-70. https://doi. org/10.1080/13645700510010872

9. Gorodner V, Horgan S, Galvani C, Manzelli A, Oberholzer J,

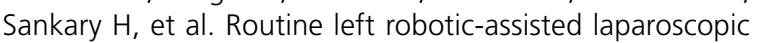
donor nephrectomy is safe and effective regardless of the presence of vascular anomalies. Transpl Int. 2006;19(8):63640. https://doi.org/10.1111/j.1432-2277.2006.00315.x

10. Laplace $B$, Ladrière $M$, Claudon $M$, Eschwege $P$, Kessler $M$, Hubert J. Robotic assisted laparoscopic living donor nephrectomy: preoperative assessment and results of 100 cases. Prog Urol. 2014;24(5):288-93. https://doi.org/10.1016/j.purol.2013.09.024

11. Cohen AJ, Williams DS, Bohorquez H, Bruce DS, Carmody IC, Reichman T, et al. Robotic-assisted laparoscopic donor nephrectomy: decreasing length of stay. Ochsner J. 2015;15(1):19-24. PMID: 25829876

12. Barman N, Palese M. Robotic-assisted laparoscopic donor nephrectomy of patient with nutcracker phenomenon. Exp
Clin Transplant. 2018;16(2):212-5. https://doi.org/10.6002/ ect.2015.0335

13. Hernandez JD, Bann SD, Munz Y, Moorthy K, Datta V, Martin $S$, et al. Qualitative and quantitative analysis of the learning curve of a simulated surgical task on the da Vinci system. Surg Endosc. 2004;18(3):372-8. https://doi.org/10.1007/ s00464-003-9047-3

14. Mazzon G, Sridhar A, Busuttil G, Thompson J, Nathan S, Briggs $T$, et al. Learning curves for robotic surgery: a review of the recent literature. Curr Urol Rep. 2017;18(11):89. https://doi. org/10.1007/s11934-017-0738-z

15. Schreuder HWR, Wolswijk R, Zweemer RP, Schijven MP, Verheijen RHM. Training and learning robotic surgery, time for a more structured approach: a systematic review. BJOG. 2012;119(2):137-49. https://doi.org/10.1111/j.14710528.2011.03139.x

16. Chung E, Grant $A B F$, Hibberd $A D$, Sprott $P$. Why potential live renal donors prefer laparoscopic nephrectomy: a survey of live donor attitudes. BJU Int. 2007;100(6):1344-6. https:// doi.org/10.1111/j.1464-410X.2007.07126.x

17. Horgan S, Vanuno D. Robots in laparoscopic surgery. Laparoendosc Adv Surg Tech A. 2001;11(6):415-9. https:// doi.org/10.1089/10926420152761950

18. Horgan S, Galvani C, Gorodner MV, Jacobsen GR, Moser F, Manzelli A, et al. Effect of robotic assistance on the "learning curve" for laparoscopic hand-assisted donor nephrectomy. Surg Endosc. 2007;21(9):1512-7. https://doi.org/10.1007/ s00464-006-9140-5

19. Galvani CA, Garza U, Leeds M, Kaul A, Echeverria A, Desai CS, et al. Single-incision robotic-assisted living donor nephrectomy: case report and description of surgical technique. Transpl Int. 2012;25(8):e89-92. https://doi.org/10.1111/j.14322277.2012.01493.x

20. LaMattina JC, Alvarez-Casas J, Lu I, Powell JM, Sultan S, Phelan MW, et al. Robotic-assisted single-port donor nephrectomy using the da Vinci single-site platform. J Surg Res. 2018;222:34-8. https://doi.org/10.1016/j.jss.2017.09.049

21. Yang A, Barman N, Chin E, Herron D, Arvelakis A, Rudow DLP, et al. Robotic-assisted vs. laparoscopic donor nephrectomy: a retrospective comparison of perioperative course and postoperative outcome after 1 year. J Robot Surg. 2018;12(2):343-50. https://doi.org/10.1007/s11701-0170741-x 